\title{
Effect of Curcumin on Gastric Emptying Induced by L-arginine in Mice
}

\author{
Yan-ting Liư1, Jing Yư ${ }^{1}$, Hong-wei Wang ${ }^{1}$, Xiao-ling Yu
}

\begin{abstract}
${ }^{1}$ Department of Physiology and Pathophysiology, Basic Medical Science of Qingdao University, Qingdao Shandong, 266021
\end{abstract}

\begin{abstract}
Objective To investigate the mechanism of curcumin administration on gastric emptying induced by L-arginine in mice. Methods Kunming male mice were divided into control group, curcumin group, L-arginine group and curcumin L-arginine combination group.There were nine mice in each group. The curcumin group and curcumin L-arginine combination group were treated with curcumin solution once a day for 15 days. From the 11th day onwards, the L-arginine group and the curcumin L-arginine combination group were given intragastric administration of L-arginine once a day for 5 days. The other groups were given solvent solution as control. The gastric emptying rate, NO content and nitric oxide synthase (NOS) activity in gastric tissue were measured after fasting for 24 hours. Results There was no significant difference between single curcumin group and the control group $(\mathrm{P}>0.05)$. But the gastric emptying rate in L-arginine group was significantly lower $(\mathrm{P}<0.01)$, the $\mathrm{NO}$ and the activity of NOS in stomach tissue was significantly higher $(\mathrm{P}<0.01)$ than that in the control group. The gastric emptying rate in curcumin L-arginine combination group was significantly higher $(\mathrm{P}<0.01)$, the NO content and the activity of NOS in gastric tissue was significantly higher $(\mathrm{P}<0.01)$ than that in L-arginine group. Conclusion curcumin can inhibit the production of no by inhibiting the NOS activity of gastric tissue, and then improve the gastric emptying of mice.
\end{abstract}

Keywords: Curcumin, L-arginine, Gastric Emptying

Curcumin is a phenolic plant of the family Curcumae extracted from the rhizome of turmeric. It has many biological activities, such as cardiovascular protection and anti-tumor ${ }^{[1,2]}$. Curcumin could significantly improve the gastrointestinal peristalsis induced by L-arginine ${ }^{[3]}$. However, the specific mechanism of curcumin was not clear.The L-arginine was the precursor of NO. NO as a non-cholinergic non-adrenergic neurotransmitter can be produced under the action of nitric oxide synthase (NOS) in vivo and plays an inhibitory role in gastrointestinal motility. The effect of curcumin on the production of $\mathrm{NO}$ was investigated by detecting the content of $\mathrm{NO}$ and the activity of NOS in gastric tissue of mice.

\section{Methods}

1.1 Animals and treatment

Thirty-six healthy male Kunming mice were randomly divided into control group, curcumin group, L-arginine group and curcumin L-arginine combination group. Curcumin group and curcumin L-arginine combination group was given curcumin suspension $200 \mathrm{mg} / \mathrm{kg}$ for 15 days. The L-arginine group was treated with L-arginine on the 11th day of gavage. The other groups were given the same amount of solvent solution as the control.

\subsection{Gastric emptying rate}

At the end of the experiment, the mice in each group fasted for 24 hours and drank freely. The mice were perfused with $0.8 \mathrm{ml}$ half fluid suspension of $80 \%$ mass fraction of Arabinol, then the mice were killed after $20 \mathrm{~min}$. The gastric cardia and pylorus were ligated by caesarean section, and the total weight of stomach was removed. The appetizers were cut along the great curvature of the stomach, as well as the contents of the stomach were washed.Then the net gastric mass was taken again, and the gastric emptying rate was calculated. The gastric emptying rate $=1-(($ total gastric weight-net gastric weight $) / 0.8 \mathrm{ml}$ Arabic gum suspension $) \times 100 \%$.

This article is published under the terms of the Creative Commons Attribution License 4.0

Author(s) retain the copyright of this article. Publication rights with Alkhaer Publications.

Published at: http://www.ijsciences.com/pub/issue/2018-03/

DOI: 10.18483/ijSci.1612; Online ISSN: 2305-3925; Print ISSN: 2410-4477 


\subsection{Determination of NO content and activity of NOS in gastric tissue}

The fresh stomach body tissue of the mice was harvested and ground into $10 \%$ volume fraction tissue homogenate at low temperature. The supernatant was obtained after centrifugation. According to the operating instructions of the NO and NOS kit built in Nanjing, the final chromogenic reaction solution was transferred to the 96-well plate by reaction with the reagent under the corresponding conditions. The absorbance of the corresponding wave length was detected by the automatic enzyme standard instrument, and then the activity of NO content and NOS was calculated quantitatively according to the protein of each gram sample.

\subsection{Statistical analysis}

SPSS17.0 software was used for statistical analysis, and the data were compared with $t$ test $(\mathrm{P}<0.05)$.

\section{Results}

2.1 Comparison of gastric emptying rate in mice Compared with the control group, the gastric emptying rate of L-arginine group decreased significantly $(\mathrm{t}=4.68, \mathrm{P}<0.01)$. The results showed that $\mathrm{L}$-arginine could significantly inhibit gastric emptying rate in mice. And compared with L-arginine group, the gastric emptying rate of curcumin L-arginine combination group was significantly increased $(\mathrm{t}=3.15, \mathrm{P}<0.01)$. The results showed that curcumin could significantly reduce the inhibitory effect of L-arginine on gastric emptying (Fig.1).

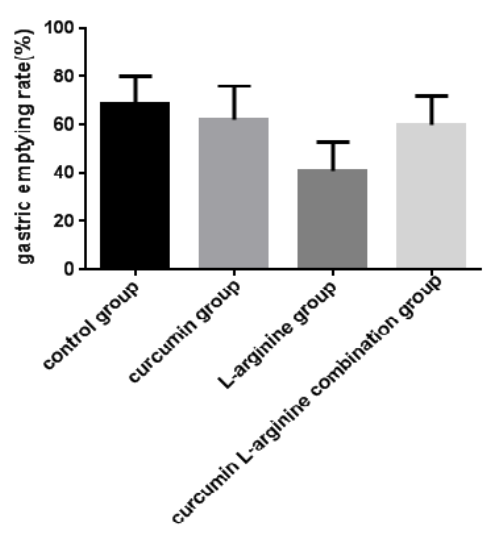

Fig. 1 comparison of gastric emptying rate in each group ( ${ }^{\bar{x}} \mathbf{+ S}, \mathbf{n}=\mathbf{9}$ )

2.2 Changes of NO content in gastric tissue of mice The content of NO in gastric tissue of L-arginine group was significantly higher than that of control group $(\mathrm{t}=3.36, \mathrm{P}<0.01)$. The results showed that $\mathrm{L}$-arginine could significantly increase the content of $\mathrm{NO}$ in gastric tissue of mice. And compared with that in L-arginine group,Curcumin L-arginine combination group recovered $(\mathrm{t}=3.98, \mathrm{P}<0.01)$. The results showed that curcumin could significantly inhibit the increase of NO content in gastric tissue induced by L-arginine (Fig.2).

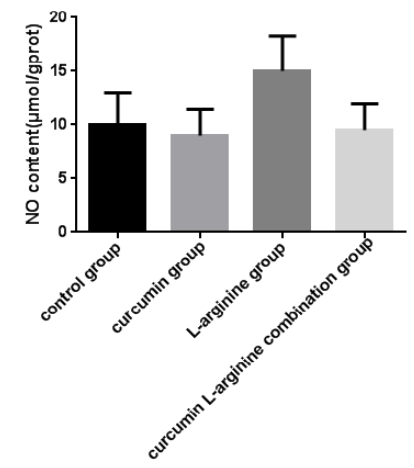

Fig.2 The NO content of each group was compared with in gastric tissues $\left(\bar{x}_{ \pm \mathrm{S}}, \mathrm{n}=9\right.$ )

\subsection{Comparison of the total NOS activity in gastric tissues}

Compared with the control group, the activities of the total NOS were significantly increased in L-arginine group $(\mathrm{t}=6.57, \mathrm{P}<0.01)$. The results showed that L-arginine could increase the activity of the total NOS in gastric tissue of mice. The activities of NOS in gastric tissue of combined group were significantly lower than those of L- arginine group, and the activity of NOS were significantly decreased $(t=4.99, \mathrm{P}<0.01)$ in the combined group than those in the L-arginine group. The results showed that curcumin could inhibit the activity of NOS in gastric tissue induced by L-arginine (Fig.3).

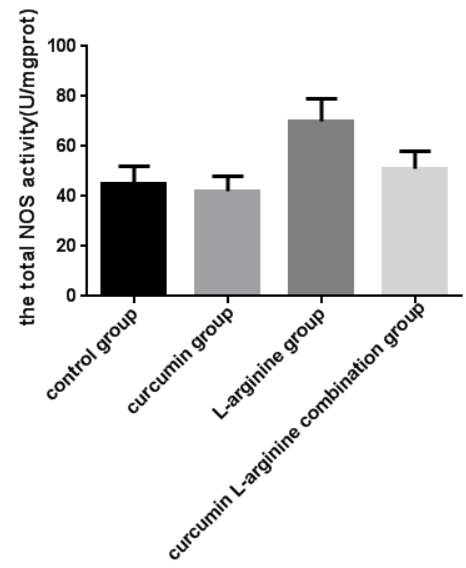

Fig. 3 the activity of the total NOS in gastric tissues of each group $\left({ }^{\bar{x}} \pm \mathrm{S}, \mathrm{n}=9\right.$ )

\section{Discussion}

Gastrointestinal motility is regulated by many factors, in which nerve and body fluids play an irreplaceable 
role in the regulation of motility. The form of gastrointestinal motility depends on the control of gastrointestinal neurons over muscles. Gastrointestinal smooth muscle is innervated by excitatory and inhibitory neurons that release excitatory and inhibitory neurotransmitters. Multiple presynaptic cell receptors are linked to complex cellular signaling pathways ${ }^{[4]}$, which involve in the contraction and relaxation of smooth muscle. NO is an important signal molecule and non-cholinergic non-adrenergic neurotransmitter in the body. The production of NO was synthesized under the catalysis of NOS and using L-arginine as substrate. $\mathrm{NO}$ in the cytoplasm was activated by guanosine cyclase, and the concentration of $\mathrm{Ca}^{2+}$ in the cytoplasm was decreased by cGMP, and the gastrointestinal smooth muscle was relaxed. NOS is the only enzyme that catalyzes the production of no by L-arginine. Detecting the activity of NOS can indirectly react with the production of NO. The total amount of NOS is mainly divided into structural NOS and inducible NOS.The structural NOS is mainly found in endothelial cells or nerve tissues, and it is also expressed in physiological state. Its activity is mainly present in macrophages and neutrophils. It is not expressed or expressed in physiological state. It can be induced by cytokines and endotoxin [5], and its activity is independent of $\mathrm{Ca}^{2+}$. Therefore, the inducible NOS can be detected simultaneously when the total of NOS is detected.

In this experiment, the gastric emptying rate was significantly decreased, NO content in gastric tissue was significantly increased, and the activities of the total of NOS were significantly increased by intragastric administration of exogenous L-arginine in mice. The results showed that $\mathrm{L}$ - arginine induced gastrointestinal peristalsis in mice was successful. In this study, curcumin pretreatment could significantly inhibit the NOS activity and NO production in gastric tissue of mice induced by L-arginine. At the same time, the gastric emptying disorder induced by L-arginine in experimental mice was significantly improved, which indicated that curcumin inhibited NOS activity and NO production. How curcumin affects the activity of NOS in mouse gastric tissue has not been reported. Previous studies have reported that curcumin inhibits the activity of inducible NOS of intestinal tract. Curcumin can also inhibit the production of many proinflammatory cytokines by inhibiting the activity of inducible NOS, which can alleviate the inflammatory reaction of mice with multidrug resistance gene deficiency, alleviate the development of colitis induced by sodium dextran sulfate, and inhibit the production of many proinflammatory cytokines ${ }^{[6]}$. NO free radicals and superoxide anions were effectively eliminated, and oxidative stress and acute gastric injury were alleviated ${ }^{[7]}$. The results of this study are similar to those of the above studies.In conclusion, curcumin may inhibit NO production to improve gastric emptying by inhibiting the activity of inducible NOS in gastric tissue. Whether curcumin can produce effect through other mechanisms, the need for further research.

\section{References}

1. Si Q, Huang L, Gong J, et al. Efficacy and safety of turmeric and curcumin in lowering blood lipid levels in patients with cardiovascular risk factors: a meta-analysis of randomized controlled trials[J]. Nutrition Journal, 2017, 16(1):68-83.

2. Feng T, Wei Y, Lee R J, et al. Liposomal curcumin and its application in cancer. [J]. International Journal of Nanomedicine, 2017, 12:6027-6044.

3. Yu J, Xu W H, Sun W, et al. Curcumin Alleviates the Functional Gastrointestinal Disorders of Mice In Vivo[J]. Journal of Medicinal Food, 2017, 20(12):1176-1183.

4. Xu Z, Liang H, Zhang M, et al. Ardipusilloside-I stimulates gastrointestinal motility and phosphorylation of smooth muscle myosin by myosin light chain kinase[J]. Korean J Physiol Pharmacol, 2017, 21(6):609-616.

5. NAGPURE BV, BIAN JS. Interaction of Hydrogen sulfide with nitric oxide in the cardiovascular system[J]. Oxidative Medicine and Cellular Longevity, 2016, 2016(2):1-16.

6. Sesarman A, Tefas L, Sylvester B, et al. Anti-angiogenic and anti-inflammatory effects of long-circulating liposomes co-encapsulating curcumin and doxorubicin on C26 murine colon cancer cells[J]. Pharmacol Rep,2017,70(2):331-339.

7. Judaki A, Rahmani A, Feizi J, et al. CURCUMIN IN COMBINATION WITH TRIPLE THERAPY REGIMES AMELIORATES OXIDATIVE STRESS AND HISTOPATHOLOGIC CHANGES IN CHRONIC GASTRITIS-ASSOCIATED HELICOBACTER PYLORI INFECTION[J]. Arquivos De Gastroenterologia, 2017,54(3):177-182. 